\title{
RELEVANCE
}

\section{Pengaruh Kepuasan Kerja, Komitmen Organisasi Dan Lingkungan Kerja Terhadap OCB (Organizational citizenship Behaviors) Karyawan Koperasi Sadar Sejahtera Sumatera Selatan}

\author{
Deniyati Zufriah $^{\mathrm{a}}$ \\ Program Studi Magister Manajemen, Universitas Islam Indonesia
}

\begin{tabular}{|c|c|}
\hline \multicolumn{2}{|c|}{$\begin{array}{l}\text { ARTICLES } \\
\text { INFORMATION }\end{array}$} \\
\hline \multicolumn{2}{|c|}{ RELEVANCE } \\
\hline \multicolumn{2}{|c|}{ Vol. 2, No. 2, Desember 2020} \\
\hline \multicolumn{2}{|c|}{ Halaman : 251-262 } \\
\hline ISSN (online) & : $2615-8590$ \\
\hline ISSN (print) & $: 2615-6385$ \\
\hline
\end{tabular}

Keywords :

Kepuasan kerja, komitmen organisasi, lingkungan kerja, $O C B$

\section{JEL classifications: \\ G11, G33}

\section{Contact Author :}

adenyyatizufriah@gmail.com,

\begin{tabular}{l} 
ABSTRACT \\
\hline Technological developments in the era of globalization are \\
increasingly fast demanding every company to develop strategies and \\
management policies, especially in the field of human resources (HR), \\
other factors that influence the work environment, and organizational \\
commitment, where the better both can create job satisfaction in \\
employees can even indirectly form organizational citizenship \\
behavior. The purpose of this study was to examine and analyze the \\
effect of job satisfaction, organizational commitment and work \\
environment on organizational citizenship behavior (OCB) employees \\
of Sadar Sejahtera Cooperative, South Sumatra. This study uses a \\
quantitative approach. The study was conducted at the Sadar Sejahtera \\
Cooperative in September 2019. The population in this study was 145 \\
respondents while the sample used was 100 respondents. The sampling \\
method uses nonprobability sampling and the sampling technique uses \\
purposive sampling. The data analysis technique used in the study is \\
multiple linear regression test. The analysis showed that partially job \\
satisfaction (p value = 0.001); organizational commitment (p value \\
O.O01) and work environment (p value = O.O25) affect Organizational \\
citizenship behavior. Furthermore, simultaneous job satisfaction, \\
organizational commitment and work environment influences \\
organizational citizenship behavior (OCB) employees of Koperasi \\
Sadar Sejahtera, South Sumatra with a calculated F value of 0,000. \\
\hline
\end{tabular}


pegawai untuk dapat berkerja optimal (Wulandari \& Prayitno, 2017). Peng \& Chiu (2010) juga menjelaskan jika lingkungan kerja dalam organisasi mempengaruhi perilaku OCB karyawan secara tidak langsung melalui kognisi afektif dan komitmen organisasi.

Lingkungan kerja yang baik secara tidak langsung akan mempengaruhi tingkat kepuasan kerja karyawan dalam suatu organisasi, dimana seorang karyawan yang merasa puas dengan kerja dan lingkungan kerjanya akan menimbulkan kepuasan dan berdampak pada produktivitas yang tinggi. Kepuasan kerja dianggap sebagai hasil dari pengalaman karyawan dalam hubungannya dengan nilai sendiri seperti apa yang dikehendaki dan diharapkan dari pekerjaannya. Masharyono et al., (2017) mengungkapkan bahwa kepuasan kerja dapat dianggap sebagai faktor utama penentu perilaku OCB, karena karyawan akan memberikan sesuatu kepada perusahaan yang telah memperlakukan mereka dengan baik. Kesediaan inilah yang kemudian dikenal sebagai organizational citizenship behavior/OCB (Waspodo \& Minadaniarti, 2012). Hubungan antara kepuasan kerja dan perilaku organizational citizenship behavior juga telah dibuktikan sebelumnya bahwa kepuasan kerja memiliki pengaruh positif dan signifikan terhadap OCB. Yahaya et al., (2014) menjelaskan jika kepuasan kerja berpengaruh positif signifikan terhadap OCBB. Hubungan antara kepuasan kerja dan Organizational citizenship behavior telah dikaji oleh beberapa peneliti, salah satunya adalah Utami \& Palupiningdyah (2016) dimana kepuasan kerja berpengaruh positif dan signifikan pada Organizational Citizenship Behaviour (OCB).

Karyawan yang merasa puas terhadap pekerjaan dan organisasi dimana karyawan bekerja seiring berjalannya waktu dapat menciptakan sebuah komitmen terhadap organisasi. Karyawan yang memiliki komitmen terhadap organisasi pasti memiliki perasaan loyalitas terhadap organisasinya sehingga mengindikasikan bahwa karyawan akan terlibat dalam OCB untuk membalas tindakan organisasi (Katz \& Kahn cit., Kucukayrak, 2010). Secara teori, individu yang memiliki komitmen organisasi yang tinggi akan bersedia melakukan berbagai tindakan diluar tanggung jawabnya sebagai karyawan. Huda (2018) menyimpulkan bahwa kepuasan kerja dan komitmen merupakan dua faktor yang dapat meningkatkan Organizational citizenship behavior (OCB).

Faktor kepuasan kerja dan komitmen yang mempengaruhi organizational citizenship behavior dibuktikan dengan masih ada beberapa dari pegawai Koperasi Sadar Sejahtera, Sumatera Selatan dengan tingkat komitmen yang rendah. Selanjutnya, hubungan antara kepuasan kerja dan komitmen organisasi juga telah dilakukan sebelumnya dimana telah dibuktikan bahwa kepuasan kerja, komitmen organisasi dan motivasi kerja berpengaruh positif dan signifikan terhadap karyawan OCB di LPD Tanjung Benoa. Artinya, semakin tinggi kepuasan kerja, dan komitmen organisasi yang dimiliki oleh karyawan, maka akan meningkatkan karyawan OCB LPD Tanjung Benoa (Putra, \& Sudibya, 2018).

Berdasarkan hasil studi pendahuluan oleh peneliti di Koperasi Sadar Sejahtera, Sumatera Selatan menunjukkan bahwa sering ditemukan karyawan yang mengundurkan diri yang menggambarkan kondisi suatu bentuk ketidaktoleransian karyawan terhadap tempat kerja yang mungkin dianggap kurang ideal, sehingga karyawan memutuskan untuk mengundurkan diri. Jika dilihat dari data pribadi karyawan dari hasil wawancara peneliti di Koperasi Sadar Sejahtera selama kurun waktu 3 tahun terakhir menunjukkan terdapat kurang lebih 10 karyawan 
yang menyatakan resign. Dengan kata lain, berbagai masalah yang terjadi di Koperasi Sadar Sejahtera tersebut dalam jangka panjang dapat berdampak buruk bagi masa depan organisasi. Adanya tingkat absensi yang tinggi diketahui secara tidak langsung menunjukkan kepuasan kerja yang rendah. Sementara menurut teori yang ada, kepuasan kerja penting bagi organisasi, dimana hal tersebut berkaitan dengan produktivitias, absensi rendah dan tingkat turnover (Yang \& Wang, 2013). Penelitian ini ingin mencela riset dengan menekankan organizational citizenship behavior pada karyawan Koperasi Sadar Sejahtera, Sumatera Selatan. Berdasarkan latar belakang yang telah diuraikan, maka permasalahan yang mendasar yaitu sejauh mana dampak kepuasan kerja, komitmen organisasi, dan lingkungan kerja terhadap $O C B$ (Organizational citizenship behaviors).

Secara praktis, penelitian ini diharapkan dapat memberikan informasi tentang bagaimana kepuasan kerja, komitmen organisasi dan lingkungan kerja mempengaruhi organizational citizenship behavior (OCB) karyawan Koperasi Sadar Sejahtera, Sumatera Selatan. Sedangkan secara teoritis, penelitian ini akan memberikan kontribusi pemikiran untuk penelitian sebelumnya sebagai dukungan, dan informasi tambahan terkait OCB karyawan, menambah pengetahuan serta pemahaman mengenai konsep kepuasan kerja, komitmen organisasi dan lingkungan kerja dalam suatu organisasi.

Organizational citizenship behaviour atau OCB memiliki arti bahwa seorang karywan bekerja lebih dari tanggung jawabnya, dimana hal ini ditentukan oleh organisasi (Ozdem, G., 2012). OCB termasuk perilaku positif yang dilakukan secara sukarela dan melampaui harapan normal pada umumnya. OCB adalah perilaku individu yang memainkan peran penting dalam efisiensi dan efektivitas organisasi. Menurut Organ, Podsakoff, \& MacKenzie (2006) dimensidimensi OCB meliputi altruism, conscientiousness, courtesy, civic virtue dan sportsmanship. Selanjutnya Zhang (2011) menjelaskan terdapat beberapa faktor yang berpengaruh terhadap organizational citizenship behavior (OCB), antara lain yaitu: Personality, Attitudes, Leadership Characteristicsdan Group Characteristics.

Selanjutnya, faktor lain yang diketahui juga mmpengaruhi OCB di tempat kerja menurut Jahangir et al., (2004) meliputi job satisfaction and organizational commitment, role perceptions, leader behaviors and leader-member exchange, fairness perceptions, individual dispositions, motivational theorie dan employee age. Kepuasan kerja merupakan perasaan puas dari karyawan terhadap pekerjaan yang telah dilakukan dalam sebuah organisasi. Kepuasan kerja ditunjukkan ketika kebutuhan seseorang di tempat kerja terpenuhi dan sesuai dengan yang diharapkan (Magdalena, 2014). Prasetio et al., (2017) mengungkapkan jika karyawan yang puas akan menunjukkan perilaku OCB yang tinggi, dimana kondisi tersebut dilakukan karena ingin membalas apa yang sudah diberikan dan perlakuan yang baik oleh organisasi. Secara teoritik, seseorang yang merasa puas terhadap pekerjaannya akan mempengaruhi kondisi emosional dan psikologis karyawan, dimana ketika individu merasa puas dengan apa yang sudah diterima dan dilakukan akan senantiasa memberikan yang terbaik bagi perusahaan tanpa diperintah. Selanjutnya, lima indikator kepuasan kerja menurut Robbins \& Judge (2009), yaitu kepuasan terhadap pekerjaan, kepuasan terhadap imbalan, kepuasan terhadap supervisi atasan, dan kepuasan terhadap rekan kerja serta kepuasan promosi. Hubungan antara kepuasan kerja dengan OCB sebelumnya juga telah dilakukan, dimana dalam hasil penelitiannya menunjukkan 
pergantian tanggung jawab pekerjaan yang diberikan juga dapat menciptakan kepuasan kerja dan menimbulkan kesediaan karyawan untuk melakukan perilaku diluar tanggung jawabnya (Montaung \& Radebe, 2018).

Individu yang memiliki keterikatan kuat dengan suatu organisasi secara tidak langsung dapat menimbulkan adanya kesepatakatan maupun komitmen dalam organisasi. Organiational commitment merupakan keadaan dimana seorang karyawan mengidentifikasi tujuan tertentu organisasi dan harapannya untuk mempertahankan posisi keanggotaan dalam organisasi (Robbins \& Timothy, 2017). Seorang karyawan yang memiliki komitmen, akan tetap bersama organisasi dalam keadaan menyenangkan atau tidak, dialami oleh organisasi. Tiga dimensi komitmen organisasi yaitu komitmen efektif, komitmen normative dan komitmen lanjutan (Robbins cit. Hidayah \& Tobing, 2018). Komitmen organisasi juga mencerminkan keterikatan emosional karyawan dengan organisasi, dimana selama ini untuk meningkatkan komitmen organisasi, organisasi harus menciptakan budaya organisasi yang diinginkan agar karyawan merasa puas dengan pekerjaannya (Pitaloka \& Sofia, 2014). Morin et al., (2010) mengungkapkan jika komitmen organisasi berhubungan positif terhadap OCB. Selain itu, terdapat beberapa factor lain yang diduga berpengaruh terhadap komitmen organisasi, antara lain yaitu karakteristik pekerjaan, karakteristik personal, karakteristik struktural dan pengalaman bekerja.

Lingkungan kerja adalah faktor kunci yang mempengaruhi kepuasan dan komitmen karyawan terhadap suatu organisasi. Lingkungan kerja yang menyediakan fasilitas aman dapat menarik perhatian karyawan dan suatu organisasi harus merancang lingkungan kerja sedemikian rupa dapat meningkatkan OCB karyawan (Hanaysha, 2016). Budiyanto \& Oetomom (2011) mengungkapkan bahwa beberapa indikator pengukuran work environment yaitu work facility, work infrastructure, dan coworkers. Hasil penelitian Nurhidayah et al., (2016) telah menunjukkan bahwa terdapat pengaruh positif antara lingkungan kerja atau work environment terhadap OCB. Secara teori, dalam lingkungan kerja terdapat iklim kerja maupun dukungan atasan yang memiliki implikasi langsung terhadap perilaku karyawan karena mencerminkan persepsi karyawan terhadap organisasi dan menentukan seberapa lama karyawan akan bertahan. Kondisi tersebut akan mempengaruhi kondisi psikologis karyawan dan merubah persepsi karyawan sehingga akan memberikan kinerja yang lebih inovatif dan memberikan perubahan lebih bebas dalam bekerja, sehingga dapat menimbulkan perilaku OCB pada organisasi (Choi, 2007).

\section{METODE}

\section{Rancangan Penelitian}

Rancangan penelitian ini menggunakan pendekatan kuantitatif, Penggunaan metode kuantitatif dilakukan karena ingin menguji teori dan model untuk menjelaskan perilaku pasar maupun hubungan antara variabel-variabel pembentuk model. Berdasarkan waktu studi, penelitian ini menggunakan studi cross-section karena data yang diperoleh diambil dalam satu waktu. Penelitian dilaksanakan di Koperasi Sadar Sejahtera yang berlokasi di Desa Biti Jaya, Kecamatan Muara Kelingi, Kab. Musi Rawas, Sumatera Selatan.. Penelitian ini dilakukan pada bulan September 2019. 
Populasi dan sampel

Populasi dalam penelitian ini adalah semua karyawan Koperasi Sadar Sejahtera. Pada penelitian ini seluruh karyawan tetap pada Koperasi Sadar Sejahtera. Populasi dalam penelitian ini adalah semua karyawan Koperasi Sadar Sejahtera. Pada penelitian ini seluruh karyawan berjumlah 145 karyawan, 100 karyawan tetap sedangkan 45 karyawan bersetatus karyawan kontrak.Teknik Pengumpulan data dan pengembangan instrumen.

Metode pengambilan sampel dalam penelitian ini menggunakan nonprobability sampling dan teknik pengambilan sampel menggunakan purposive sampling. Teknik ini terjadi ketika peneliti memilih anggota sampel yang memenuhi beberapa kriteria (Cooper dan Schindler, 2003). Metode pengumpulan data penelitian ini menggunakan data primer yang didapat dengan menyebarkan kuisioner kepada karyawan tetap Koperasi Sadar Sejahtera yang sudah bekerja minimal 3 tahun. Oleh karena itu, sampel yang digunakan dalam penelitian ini sebanyak 100 responden.

Pengujian instrumen dilakukan dengan uji validitas dan reliabilitas, setelah itu dilakukan uji asumsi klasik mulai dari uji multikolinearitas dan uji normalitas serta uji heteroskedastisitas. Uji validitas digunakan untuk mengetahui valid tidaknya suatu kuesioner untuk mengukur sebuah konsep. Kuesioner dikatakan valid apabila item pertanyaan kuesioner mampu mengungkapkan sesuatu yang akan diukur (Sekaran dan Bougie, 2013). Pengujian validitas konvergen menggunakan analisis faktor konfirmatori dengan bantuan IBM SPSS 21, dimana setiap item pernyataan harus mempunyai koefisien nilai factor loading lebih besar dari 0,50 agar dapat dinyatakan valid (Hair et al., 2006). Reliabiltas adalah sejauh mana pengukuran terbebas dari error dan menghasilkan hasil yang konsisten. Pengujian reliabilitas dilakukan dengan melihat nilai Cronbach's Alpha dengan bantuan program IBM SPSS 21.

Teknik Analisis Data

Teknik analisis data yang digunakan dalam penelitian ini adalah analisis regresi linear berganda. Analisis regresi dalam penelitian ini digunakan untuk menguji hipotesis penelitian. Teknik analisis regresi ini secara statistik dapat menentukan pengaruh antara variabel dengan melihat indikator pada nilai statistik $F$, koefisien determinan $\left(\mathrm{R}^{2}\right)$ dan statistik $t$.

\section{HASIL DAN PEMBAHASAN}

Hasil penelitian ini uji hipotesis terhadap variabel dalam penelitian yaitu kepuasan kerja, komitmen organisasi, lingkungan kerja dan organizational citizenship behavior (OCB) karyawan Koperasi Sadar Sejahtera, Sumatera Selatan yang akan disajikan sebagai berikut.

Pengujian hipotesis pada penelitian ini menggunakan metode analisis regresi linear berganda. Untuk mengetahui tingkat ketepatan fungsi regresi, diukur dari goodness of fit yang secara statistik dapat dilihat dari nilai adjusted $\mathrm{R}^{2}$, nilai statistik t, dan nilai statistik F. Apabila nilai uji statistik $\mathrm{t}$ berada di bawah 0,05, maka Ho ditolak dan Ha diterima.

Hipotesis pertama hingga hipotesis keempat bertujuan untuk menguji dan menganalisis pengaruh kepuasan kerja, komitmen organisasi, dan lingkungan kerja terhadap organizational citizenship behavior (OCB) karyawan Koperasi Sadar Sejahtera, Sumatera Selatan. Hasil pengujian hipotesis pertama hingga hipotesis keempat dapat dilihat pada Tabel 10 berikut. 
Tabel 10. Hasil Uji Analisis Regresi Berganda

\begin{tabular}{|c|c|c|c|c|}
\hline Variabel & Koef. & t hitung & Sig. & Keputusan \\
\hline Kepuasan Kerja & 0,269 & 3,302 & 0,001 & Signifikan \\
\hline Komitmen Organisasi & 0,338 & 3,285 & 0,001 & Signifikan \\
\hline Lingkungan Kerja & 0,230 & 2,272 & 0,025 & Signifikan \\
\hline \multicolumn{2}{|l|}{$F_{\text {hitumg }}$} & Adjusted R Square & \multicolumn{2}{|c|}{0,397} \\
\hline
\end{tabular}

Sumber: Data Primer Diolah, 2019.

Pengujian Hipotesis 1 hingga Hipotesis 4 dalam penelitian ini menggunakan metode regresi berganda. Nilai Adjusted $R^{2}$ mempunyai nilai sebesar 0,397. Hal ini berarti 39,7\% Organizational citizenship behavior (OCB) dapat dijelaskan oleh variabel-variabel independen, yakni Kepuasan Kerja, Komitmen Organisasi dan Lingkungan Kerja sedangkan sisanya (100\% $-39,7 \%=60,3 \%$ ) dijelaskan oleh variabel lain di luar penelitian ini.

\section{Pengaruh Kepuasan Kerja terhadap Organizational Citizenship Behavior (OCB)}

Berdasarkan Tabel 10 diperoleh koefisien regresi variabel kepuasan kerja sebesar 0,269. Pada taraf signifikansi (p) 0,001 <0,05, sehingga dapat disimpulkan bahwa Kepuasan Kerja secara parsial berpengaruh positif signifikan terhadap Organizational citizenship behavior (OCB). Hal ini berarti sesuai dengan $\mathrm{H}_{\mathrm{a}}$. Secara teori, karyawan yang merasa puas dengan pekerjaanya akan memberikan segala kemampuan dan keahlian yang dimiliki untuk menyelesaikan pekerjaan. Ketika karyawan sudah memberikan semaksimal mungkin kemampuannya dalam bekerja maka secara tidak langsung hal ini akan berdampak pada peningkatan apresiasi dan penghargaan yang diberikan organisasi. Jika individu puas dengan pekerjaan mereka, maka sebagai timbal baliknya individu tersebut akan melakukan semua pekerjaan secara sukarela tanpa harus diperintahkan terlebih dahulu atau dengan kata lain, individu yang merasa puas akan membalasnya melalui OCB (Fassina et al., 2008). Teori Robbins \& Timothy (2017) telah membuktikan bahwa kepuasan kerja dapat menimbulkan sebuah kepercayaan antara organisasi dengan karyawan, sehingga secara tidak langsung hal ini dapat menimbulkan perilaku OCB.

Dalam penelitian ini, karyawan Koperasi Sadar Sejahtera diketahui cukup memiliki kepuasan kerja yang baik, sehingga secara tidak langsung hal tersebut dapat mendorong karyawan untuk membalas budi terhadap organisasi. Jika tingkat kepuasan kerja karyawan dapat dipengaruhi oleh sejumlah faktor, antara lain lingkungan kerja yang mendukung, kepemimpinan, hubungan dengan rekan kerja dan komitmen organisasi (Motaung \& Radebe, 2018). Bahkan karakteristik individu diketahui juga dapat mempengaruhi tingkat kepuasan kerja seperti usia, tingkat pendidikan, status perkawainan dan jenis kelamin.

Seseorang yang merasa puas terhadap pekerjaannya akan mempengaruhi kondisi emosional dan psikologis karyawan, dimana ketika individu merasa puas dengan apa yang sudah diterima dan dilakukan akan senantiasa memberikan yang terbaik bagi perusahaan tanpa diperintah maupun diminta oleh atasan. Dengan kata lain, seorang karyawan yang merasa puas terhadap apa yang sudah diperoleh dapat meningkatkan kinerja dan tanggung jawabnya 
terhadap pekerjaan di luar kewajiban (Kcucukayrak, 2010). Karyawan dengan tingkat kepuasan kerja cukup tinggi akan sangat dengan mudah mengenali nilai-nilai dan tujuan organisasi dimana nantinya dapat meningkatkan kenyamanan dan kebersamaan antar anggota karyawan satu sama lain dalam sebuah organisasi Jordan et al., (2017). Hasil peneltian ini juga sejalan dengan penelitian Gunay (2018) menambahkan dalam hasil penelitiannya jika kepuasan kerja mempengaruhi OCB karyawan.

Karyawan yang merasa puas dengan pekerjaan yang telah dilakukan pada umumnya akan menunjukkan sikap positif terhadap pekerjaan dan akan mengerahkan segala upaya yang sangat besar demi menyelesaikan tanggung jawab. Pernyataan tersebut diperkuat oleh teori sebelumnya yang menyatakan bahwa jika karyawan yang puas akan menunjukkan perilaku OCB yang tinggi, dimana kondisi tersebut dilakukan karena ingin membalas apa yang sudah diberikan dan perlakuan yang baik oleh organisasi (Prasetio et al., 2017). Dengan kata lain, karyawan akan memiliki sikap OCB setelah merasa puas dengan pekerjaanya. Secara teoritik, karyawan yang merasa puas dengan pekerjaan yang telah dilakukan selama di suatu organisasi memberikan dampak positif bagi dirinya dikarenakan karyawan akan melakukan tugas dengan sukarela diluar tanggung jawabnya sebagai timbal balik dari apa yang sudah diperoleh. Berbeda dengan kondisi jika karyawan tidak merasa puas dengan pekerjaan yang telah dilakukanya maka secara tidak langsung dapat berdampak negatif terhadap komitmen yang dimiliki sehingga tidak akan melakukan pekerjaan dengan baik.

\section{Pengaruh Komitmen Organisasi terhadap Organizational Citizenship Behavior (OCB)}

Berdasarkan Tabel 10 diperoleh koefisien regresi Komitmen Organisasi sebesar 0,338. Pada taraf signifikansi (p) 0,001 < 0,05, sehingga dapat disimpulkan bahwa Komitmen Organisasi secara parsial berpengaruh positif signifikan terhadap Organizational citizenship behavior (OCB). Hal ini berarti sesuai dengan $\mathrm{H}_{\mathrm{a}}$. Individu yang memiliki keterikatan kuat dengan suatu organisasi secara tidak langsung dapat menimbulkan adanya kesepatakatan maupun komitmen dalam organisasi. Selain itu, individu yang mengalami keadaan psikologis yang menjaga individu dalam organisasi dan memiliki keterikatan emosional dengan karyawan lain cenderung akan melakukan pekerjaan diluar tanggung jawab yang seharusnya diberikan atau dikenal dengan perilaku OCB (Pitaloka \& Sofia, 2014). Individu dengan komitmen organisasi yang tinggi cenderung akan memiliki kepercayaan yang cukup besar pada tujuan dan nilai suatu organisasi, dan kesediaan untuk terus menjadi salah satu anggota organisasi (Atteya, 2012). Kesediaan tersebut yang nantinya akan mendorong individu tersebut untuk secara sukarela tanpa diminta terlebih dahulu untuk memberikan tenaga dan waktunya pada organisasi.

Katz \& Kahn cit., Kucukayrak, (2010) mengungkapkan jika karyawan yang berkomitmen tinggi terhadap organisasi akan melakukan perilaku ekstra diluar peran dan tanggung jawabnya sebagai karyawan yang membuat organisasi tetap kompetitif. Adapun perilaku ekstra diluar peran dan tanggung jawab seorang karyawan tersebut dikenal dengan perilaku Organizational citizenship behavior/OCB. Penelitian yang hampir sama juga menunjukkan bahwa komitmen organisasi berpengaruh positif dan signifikan terhadap perilaku OCB (Patra \& Aima, 2018). Korelasi dimensi tertinggi dari komitmen organisasi dengan OCB adalah dimensi dari komitmen normatif. Kondisi ini menunjukkan bahwa komitmen dibentuk 
dengan alasan moral/etis bagi karyawan, membentuk perilaku yang menunjukkan tanggung jawab karyawan dalam kehidupan organisasi perusahaan. Sejalan dengan hasil penelitian Nurdin \& Nawangsari (2019) dimana terdapat pengaruh yang signifikan antara komitmen organisasi dan kepuasan karyawan pada tingkat perilaku OCB karyawan LPPI.

Komitmen merupakan salah satu masalah perilaku dalam organisasi yang dihadapi oleh sebagian besar organisasi dengan alasan bahwa tidak semua karakteristik karyawan sama. Komitmen organisasi sendiri timbul dari keterikatan secara emosional karyawan dengan suatu organisasi. Jordan et al., (2017) mengungkapkan jika komitmen organisasi didefinisikan sebagai identifikasi individu dan keterlibatan seseorang dengan organisasi tertentu dan merupakan cerminan dari kondisi psikologis individu. Komitmen organisasi diketahui juga akan mempengaruhi perasaan karyawan tentang suatu organisasi dan merasa menjadi bagian dari suatu organisasi, yang nantinya dapat memiliki pengaruh terhadap kesediaan karyawan untuk memajukan nilai-nilai organisasi dan golongan. Seorang karyawan dengan komitmen efektif akan melekat secara psikologis pada organisasi, tinggal lebih lama dan menciptakan keramahan terhadap organisasi (Mamman et al., 2011).

Keterikatan emosional dapat terjalin dengan baik jika keduanya, yaitu organisasi dan karyawan saling bekerja sama dan memberikan hubungan timbal balik yang seimbang, dimana karyawan akan memberikan segala keterampilan dan pengetahuan serta tenaga yang dimiliki untuk meningkatkan pertumbuhan dan perkembangan organisasi. Selan itu, sebagai organisasi sudah seharusnya memberikan dan menyediakan fasilitas, dan tanggung jawab pekerjaan sesuai dengan kemampuan karyawan. Berdasarkan uraian tersebut, dapat dikatakan bahwa adanya kepribadian individu yang berbeda dalam suatu organisasi dapat membatasi perilaku Colbert et al (cit. Hitlan \& Noel, 2009). Adanya kepribadian karyawan akan menentukan perilaku atau sikap yang muncul akibat dari suatu perilaku, baik perilaku positif maupun negatif. Singkatnya, individu yang memiliki karakteristik kepribadian tertentu tidak akan terlibat dalam bentuk perilaku yang menyimpang, dalam organisasi.

\section{Pengaruh Lingkungan Kerja terhadap Organizational citizenship behavior (OCB)}

Berdasarkan Tabel 10 diperoleh koefisien regresi lingkungan kerja sebesar 0,230. Pada taraf signifikansi (p) 0,025 < 0,05, sehingga dapat disimpulkan bahwa Lingkungan Kerja secara parsial berpengaruh positif signifikan terhadap Organizational citizenship behavior (OCB). Hal ini berarti sesuai dengan $\mathrm{H}_{\mathrm{a}}$.

Suatu organisasi dengan lingkungan kerja yang baik, terutama kondisi fisik, iklim yang komuikatif, dan aturan serta prosedur yang sesuai dengan strategi organisasi dapat meningkatkan perilaku OCB. Dengan kata lain, ketika lingkungan kerja dalam organisasi kondusif maka OCB juga akan meningkat. Pernyataan tersebut sejalan dengan hasil penelitian Nurhidayah et al., (2016) telah menunjukkan bahwa terdapat pengaruh positif antara lingkungan kerja atau work environment terhadap OCB. Jika dilihat secara teori, seorang individu yang bekerja dilingkungan kerja yang menenangkan dan menyenangkan dengan fasilitas yang memadai cenderung akan mempengaruhi kondisi psikologis karena merasa 
senang, sehingga individu akan melakukan pekerjaan yang menjadi tanggung jawabnya secara sukarela dan memberikan seluruh tenaganya untuk tujuan organisasi.

Wulandari \& Prayitno, (2017) menambahkan bahwa lingkungan kerja positif dan signifikan terhadap OCB pegawai. Hasil penelitian yang sama juga telah dibuktikan oleh Budiyanto \& Oetomo (2011) jika lingkungan kerja berpengaruh positif dan signifikan terhadap OCB. Lingkungan kerja yang baik dan adanya kecerdasan emosioanl yang terjalin antara karyawan Koperasi Sadar Sejahtera yang dibangun melalui kegiatan rutin yang diadakan oleh organisasi dapat membangun perilaku organizational citizenship behavior. Choi (2007) menambahkan jika lingkungan kerja dapat mempengaruhi kondisi psikologis karyawan dan merubah persepsi karyawan sehingga akan memberikan kinerja yang lebih dan memberikan perubahan lebih bebas dalam bekerja, dimana hal tersebut dapat menimbulkan perilau OCB pada organisasi.

Secara teori, lingkungan kerja yang nyaman dan membuat karyawan merasa nyaman akan mempengaruhi kondisi psikologis. Jika dilihat dari sisi psikologis, lingkungan suatu organisasi, baik dari rekan kerja, fasilitas maupun atasan dapat menciptakan persepsi tersendiri bagi karyawan sehingga memberikan perubahan yang lebih bebas dalam melakukan pekerjaannya. Keterkaitan antara kondisi emosional individu dengan perilaku OCB diketahui telah dibuktikan sebelumnya. Berdasarkan hasil penelitian Koning \& Kleef (2015) menjelaskan jika kondisi emosional para pemimpin organisasi berperan dalam meningkatkan maupun mengurangi perilaku sukarela atau organizational citizenship behavior (OCB). Jain \& Kaur (2014) mengungkapkan bahwa lingkungan kerja yang kondusif dan baik dapat meningkatkan hasil dan produktivitas kerja karyawan dalam organisasi dan berdampak pada kepuasan kerja. Manajemen sumber daya manusia yang efisien dan lingkungan kerja yang efektif juga mempengaruhi pertumbuhan dan perkembangan ekonomi organisasi.

Jika dilihat dari hasil analisis regresi secara simultan dapat diketahui bahwa kepuasan kerja, komitmen organisasi dan lingkungan kerja berpengaruh signifikan dan positif terhadap Organizational citizenship behavior (OCB). Hal ini dibuktikan dengan nilai F hitung yaitu sebesar 22,714 dan nilai signifikansi seluruh variabel independen sebesar 0,000 di bawah nilai $\alpha(0,05)$, sehingga variabel-variabel independen, yakni Kepuasan Kerja, Komitmen Organisasi dan Lingkungan Kerja terhadap berpengaruh secara bersama-sama terhadap Organizational citizenship behavior (OCB). Hal ini berarti sesuai dengan Ha.

\section{PENUTUP}

\section{Simpulan}

Berdasarkan hasil analisis data dan pembahasan sebelumnya, maka dapat disimpulkan bahwa kepuasan kerja berpengaruh terhadap organizational citizenship behavior (OCB) karyawan Koperasi Sadar Sejahtera, Sumatera Selatan. Komitmen organisasi berpengaruh terhadap organizational citizenship behavior (OCB) karyawan Koperasi Sadar Sejahtera, Sumatera Selatan. Selanjutnya, lingkungan kerja berpengaruh terhadap organizational citizenship behavior (OCB) karyawan Koperasi Sadar Sejahtera, Sumatera Selatan. Kepuasan kerja, 
komitmen organisasi dan lingkungan kerja secara simultan berpengaruh terhadap organizational citizenship behavior (OCB) karyawan Koperasi Sadar Sejahtera, Sumatera Selatan

\section{Saran}

Berdasarkan kesimpulan penelitian yang telah diuraikan sebelumnya, peneliti menyadari bahwa masih terdapat banyak kekurangan di dalam penulisan tesis berikut. Oleh karena itu, peneliti memberikn beberapa saran untuk pertimbangan sebagai penyempurnaan sebagai berikut: 1) Penelitian selanjutnya diharapkan dapat menggunakan variabel lain di luar kepuasan kerja, komimen organisasi, lingkungan kerja dan perilaku OCB untuk menunjukkan hal lain yang turut mempengaruhi tingkat organizational citizenship behavior (OCB); 2) Untuk penelitian selanjutnya, peneliti disarankan untuk melakukan penelitian jangka panjang agar perilaku OCB yang dilakukan tidak hanya diambil dari kuesioner yang diberikan tetapi juga sesuai dengan data valid mengenai statistik kualitas karyawan tersebut; 3) Hasil penelitian ini diharapkan dapat dijadikan sebagai acuan perusahaan untuk lebih memperhatikan hal-hal yang dapat meningkatkan kepuasan kerja dan menciptakan lingkungan kerja kondusif serta menumbuhkan komitmen dalam organisasi karena dapat berpengaruh terhadap keterlibatan karyawan dalam perilaku OCB.

\section{DAFTAR PUSTAKA}

Atteya, N.M. (2012). Testing the Impact of the Human Resource Management Practices on Job Performance: An Empirical Study in the Egyptian Joint Venture Petroleum Companies. International Journal of Business and Social Science Vol. 3 No. 9; May.

Budiyanto, \& Oetomo, H.W. 2011. The Effect of Job Motivation, Work Environment and Leadership on Organizational citizenship behavior, Job satisfaction and Public Service Quality in Magetan, East Java, Indonesia. International Journal of Economics and Management Engineering Vol:5, No:3,

Choi, J.N. 2007. Change-oriented organizational citizenship behavior: effects of work environment characteristics andintervening psychological processes. Journal of Organizational Behavior J. Organiz. Behav. 28, 467-484 (2007) Published online 5 January 2007 in Wiley InterScience (www.interscience.wiley.com) DOI: 10.1002/job.433

Cooper Donald R. \& Pamela S. Schindler. 2003. "Business Research Method Eight Edition”. New York. McGraw Hill.

Fassina, N.E., Jones, D.A., \& Uggerslev, K.L. (2008). Relationship Clean-Up Time: Using Meta-Analysis and Path Analysis to Clarify Relationships Among Job satisfaction, Perceived Fairness, and Citizenship Behaviors. Journal of Management, Vol. 34 No. 2, April 2008 161-188, DOI: 10.1177/0149206307309260

Ghozali, Imam. 2011. Analisis Multivariate dengan Program IBM SPSS 19. Semarang: Badan Penerbit Undip.

Gunay, G.Y. 2018. Relationship between Job Satisfaction, Organizational citizenship behavior and Employee Performance: Sample of Edirne Financial Office Employees in Turkey. American International Journal of Contemporary Research Vol. 8, No. 1, March. 
Hanaysha, J. 2016. Testing the Effects of Employee Engagement, Work Environment, and Organizational Learning on Organizational Commitment. Procedia - Social and Behavioral Sciences 229 ( 2016 ) $289-297$

Hitlan, R.T \& Noel, J. 2014. The influence of workplace exclusion and personality on counterproductive work behaviours: An interactionist perspective. European Journal of Work and Organizational Psychology 2009, 18 (4), 477-502

Hidayah, T., \& Tobing, D.S.K. (2018). The Influence Of Job satisfaction , Motivation, And Organizational Commitment To Employee . International Journal Of Scientific \& Technology Research Volume 7, Issue 7, July

Huda, K.(2018. Pengaruh Kepuasan Kerja Terhadap Organizational citizenship behavior (Ocb) Komitmen Organisasi Sebagai Variabel Intervening(Studi Kasus Pada Pt Citayasah Perdana). Jurnal OPTIMA Volume II Nomor 1.

Jahangir, N., Akbar, M.M., \& Haq, m. 2004. Organizational citizenship behavior: Its Nature And Antecedents. Brac University Journal, vol. I, no. 2, 2004, pp. 75-85

Jain, R. \& Kaur, S. 2014. Impact Of Work Environment On Job satisfaction . International Journal of Scientific and Research Publications, Volume 4, Issue 1, January

Jordan, G., Miglic, G., Todorovic, I. 7 Maric, M. 2017. Psychological Empowerment, Job satisfaction and Organizational Commitment Among Lecturers in Higher Education: Comparison of Six CEE Countries. Organizacija, Volume 50 Research Papers Number 1, February

Koning, L.F., \& Kleef, G.A. 2015. Howleaders' emotional displays shape followers' organizational citizenship behavior. The Leadership Quarterly 26 (2015) 489-501

Kucukbayrak, R. 2010. An Integrative Model Of Transformational Leadership, Organizational Commitment, Job satisfaction And Organizational citizenship behavior. Thesis: The Graduate School Of Social Sciences Of Middle East Technical University.

Lestari, E.R., \& Ghaby, N.K.F. 2018. The Influence of Organizational citizenship behavior (OCB) on Employee's Job satisfaction and Performance. Industria: Jurnal Teknologi dan Manajemen Agroindustri Volume 7 Nomor 2: 116-123.

Magdalena, S.M. 2014. The effects of organizational citizenship behavior in the academic environment. Procedia - Social and Behavioral Sciences 127 (2014) 738 - 742.

Mamman, A., Kamoche, K. \& Bakuwa, R. 2012. Diversity, organizational commitment and organizational citizenship behavior: An organizing framework. Human Resource Management Review 22 (2012) 285-302

Morin, A., Vandenberghe, C., Boudrias, Mdore, Morizot, \& Tremblay, M. 2010. Affective commitment and citizenship behaviors across multiple foci. Journal of Managerial Psychology Vol. 26 No. 8, 2011 pp. 716-738.

Motaung, T.L. \& Radebe, P.Q. 2018. Organisational Commitment and Job satisfaction as Antecedents of Organisational Citizenship Behaviour. Journal of Economics and Behavioral Studies (ISSN: 2220-6140)Vol. 10, No. 6A, pp. 109-122.

Nurdin, M.A., \& Nawangsari, L.C. 2019. The Effect of Followership, Organizational Commitments, and Job satisfaction on Organizational Citizenship Behaviour (OCB) Indonesia Banking Development Institution. International Journal of Scientific and Research Publications, Volume 9, Issue 2, February.

Nurhidayah, A., Nurhattati, \& Matin. 2016. Organizational Culture and Work Environment: Its Effect on Teachers Organizational citizenship behavior (OCB). International Journal of Science and Research (IJSR) ISSN (Online): 2319-7064 Index Copernicus Value (2016): 79.57 | Impact Factor.

Ozdem, G. (2012). The Relationship Between The Organizational citizenship behaviors And The Organizational And Professional Commitments Of Secondary School Teachers. 
Journal Of Global Strategic Management | V. 6 | N. 2 | 2012-December 47-64 | DOI: 10.20460/JGSM.2012615773

Patra, A. \& Aima, M.H. 2018. The Effect of Organizational Culture and Job satisfaction on Organizational Commitments and the Implementation on Organizational citizenship behavior in Employees of Pt. Bali Towerindo Sentra Tbk. International Journal of Scientific and Research Publications, Volume 8, Issue 12, December 2018 320, ISSN 2250-3153.

Peng, J.C. \& Chiu, S.F. 2010. An Integrative Model Linking Feedback Environment and Organizational citizenship behavior. The Journal of Social Psychology, 2010, 150(6), 582-607

Pitaloka, E. \& Sofia, I.P. 2014. The Affect Of Work Environment, Job satisfaction , Organization Commitment On Ocb Of Internal Auditors. International Journal of Business, Economics and Law, Vol. 5, Issue 2 (Dec.) ISSN 2289-1552.

Prasetio, A.P., Yuniarsih, T., \& Ahman, E. 2017. Job satisfaction , Organizational Commitment, and Organizational Citizenship Behaviour in State-owned Banking. Universal Journal of Management 5(1): 32-38, 2017 http://www.hrpub.org.

Robbins, S.P., \& Judge, T. (2017). Organization Behavior 7Ed. New York: Pearson.

Sekaran, Uma \& Bougie, R. 2013. Research Methods for Business: A Skill-Building Approach, John Wiley and Son, inc: London.

Wang, Y. 2015. Examining organizational citizenship behavior of Japanese employees: a multidimensional analysis of the relationship to organizational commitment. The International Journal of Human Resource Management, 2015 Vol. 26, No. 4, 425-444, http://dx.doi.org/10.1080/09585192.2011.560882.

Waspodo, A. \& Minadaniati, L. 2012. Pengaruh Kepuasan Kerja Dan Iklim Organisasi Terhadap Organizational citizenship behavior (Ocb) Karyawan Pada Pt. Trubus Swadaya Depok. Jurnal Riset Manajemen Sains Indonesia (JRMSI)|Vol. 3, No. 1

Wulandari, D.A., \& Prayitno, A. 2017. Pengaruh Motivasi Kerja Dan Lingkungan Kerja Terhadap Organizational citizenship behavior Dengan Komitmen Organisasi Sebagai Variabel Intervening. Jurnal Penelitian Ekonomi dan Bisnis, 2 (1), 2017, Hal : 46-57

Yahaya, A., Yahaya, N., Ma'alip, H., Ramli, J., \& Kamal, M. 2012. The Relationship Between the Occupational Stress, Organizational Commitment, and Job satisfaction With Organizational citizenship behavior. Archives Des Sciences, ISSN 1661-464X, Vol 65, No. 3;Mar 